\title{
El neerlandés, la lengua de más de veinte millones de europeos
}

\author{
Victor Valembois ${ }^{1}$ \\ Universidad de Costa Rica
}

\section{RESUMEN}

Se analiza la situación actual del neerlandés desde tres perspectivas: el camino semántico-histórico recorrido en cuanto al nombre mismo del neerlandés; los nexos de ese vehículo expresivo. en lo lingüístico y lo literario, con el español y lo hispano, con hincapié en vínculos con Centroamérica; y el neerlandés en el contexto pasado y actual de las lenguas europeas con miras a su futuro, ahora que estamos en un mundo global.

\section{Abstract}

The current situation of the language spoken in the Netherlands is analyzed here from three different perspectives: it is approached historically and semantically to clarify the name of the language; a number of linguistic and literary ties with this language are discussed, with emphasis on the Spanish language and Central America; and the future of the Dutch language is addressed taking into account the past and present context of European languages, now that we are in a globalized world.

Palabras clave: neerlandés, holandés, Holanda, los Países Bajos

Keywords: Dutch, Holland, The Netherlands

$\bar{l}$ Correo electrónico: valembois@ice.co.cr. 
Primero te sentarás un tanto ale jado, así, en el pasto. Te miraré de reojo y no dirás nada. La lengua se presta a la confusión.

Perocada día te podrás acercar otro poquito.

Antoine de Saint-Exupéry, El

Principito.

Para Antoon Thybergin, belga, holandés, centroamericano y ciudadano del mundo, donde sea que se encuentre ahora.

El neerlandés, ¿y eso qué es; irlandés dijo? De partida entre mis lectores puede haber cierta sensación de inseguridad: ¿a qué lengua se refiere, qué es exactamente y quiénes la hablan? Estoy seguro de que tanto en el plano individual como en el colectivo, a mucha gente de mi idioma materno se le ha presentado este pequeño episodio, simpático si se quiere, pero al mismo tiempo revelador de desconocimiento.

Contestar, como lo hace un librito, desde su mismo título, que se trata de «la lengua de veinte millones de neerlandeses y flamencos» no es sino trasladar la dificultad. Como si la indicación de una cantidad en sí bastara. Esa perspectiva recuerda también la evocada por el personaje central de Saint-Exupéry, que encontraba que los grandes siempre necesitan cifras, cantidades, valor monetario, para ubicarse en cuanto a qué es un objeto o lo que vale una persona. Esa dimensión también cuenta, desde luego, en el concierto mundial, pero además a escala micro, que es la de los encuentros reales, de tú a tú.

Describir el asunto desde el punto de vista cualitativo es otro callejón sin salida: ¿qué es «calidad» para un idioma en sí o para un idioma en confrontación con otros, como ocurre cada vez más, hoy, en un mundo dinámico y de interferencias tan variadas como múltiples? De allí la dificultad: refugiarse únicamente en el aspecto filológico es peligroso, hasta monocorde, además de orientarse a un público más de especialistas, cuando esta redacción, surgida en el contexto fortuito de la celebración de ciento cincuenta años de vínculos de los Países Bajos con Costa Rica, postula una respuesta a la no tan inocente pegunta 
inicial, tanto para gente del ámbito oficial, como de los círculos privados. Es un aporte a la reconstrucción histórica de las relaçiones entre ambas partes.

\section{Primera parte: precisiones terminológicas para uso «cir- cumcaribe» $^{2}$}

\subsection{El nombre lo dice todo, sí pero...}

Tenían razón los latinos con su aforismo de que nomen est omen; el nombre contiene un indicio, una pista. Desde luego, revelador es el caso que nos ocupa. La frase romana lo expresa además con chispa, pero esta vez conectada a todo un imprescindible tejido de background information, como se lo llama en inglés. En definitiva, este escrito entre lo periodístico y lo académico se propone contestar a esa no tan inocente pregunta inicial: ¿con qué se come eso, el neerlandés? La respuesta no tiene pretensión de ser exhaustiva, pero sí coherente y comprensible para el público de habla hispana, mayoritariamente centroamericano, al que va orientada.

\subsection{Cuatro términos, ¿cuatro enredos?}

Desde luego, para entenderse respecto de ciertos conceptos resulta sumamente útil explicar qué se entiende por ellos. «Definamos los términos» fue una sana obsesión de Voltaire. Pero los cuatro vocablos siguientes prueban que eso en sí no basta, ya que la confusión, tanto en el Caribe como en el ámbito mundial, tiene su origen en acepciones históricamente disímiles. Pese al propósito didáctico y

$2 \quad$ Para más información sobre los temas tratados consultar: Timothy Garton Ash, «La orquesta europea", en El País (Madrid). 8 de junio de 2001: Lieven De Late. "The Language of Flanders and the Netherlands", Flanders (Bélgica), n 47, setiembre del 2000. pp. 20-24; K. Heeroma, El neerlandés en el mundo, publicación oficial, La Haya, Países Bajos, 1967, pp. 2-7; Reiner Salverda, "The Other Languages of the Netherlands». TLC (The Low Countries), edición «Stichting Ons Erfdeel», Bélgica, n 8, pp. 245-252: O. Vandeputte y otros, El neerlandés, la lengua de veinte millones de neerlandeses y flamencos, edición "Stichting Ons Erfdeel», Bélgica. 4 reimpresión, 1996; O. Vandeputte, «Qu'est-ce que le néerlandais?», Septentrion. revista cultural de los Países Bajos y Bélgica, año vi. n 1. 1977, pp. 23-37. 
esclarecedor que anima el presente escrito, resulta complicado el asunto, pues los respectivos vocablos de flamenco, holandés, neerlandés y belga, con sus derivados y afines, no solo son complejos en sí, en dimensión sincrónica, actual, sino que en diacronía se ha utilizado una misma etiqueta para cubrir contenidos diferentes y llenos de connotaciones. Si leemos superficialmente cada una de las palabras anunciadas, sin rellenarlos con su correspondiente carga léxica e histórica, puede ser que detrás de los nombres haya cada vez muchas trampitas y malentendidos.

\subsection{Flamencos sí, pero de Flandes}

Que los nombres como tales y, peor, en traducciones, son trampas mortales, lo prueba el caso de este territorio que ahora ocupa dos de las diez provincias de Bélgica, una al lado de la otra, a partir del Canal de la Mancha, estrecho marítimo que separa Gran Bretaña de la masa continental europea. Se trata de Flandes Occidental y de Flandes Oriental, división de mera incidencia administrativa, ya que históricamente provienen de un mismo condado. Brujas — conocida también como la «Venecia del Norte»- es la capital de la primera y ante su frecuente evocación en 2002 como una de las rotativas ciudades culturales europeas, conviene enderezar el entuerto: su nombre viene del neerlandés brug (en inglés bridge, puente) por lo que no guarda relación alguna con mujeres malévolas, a las que les dicen «brujas», pese a que la homonimia en español se presta a tramposas asociaciones.

Esta parte pujante de la actual Europa adquiere fuerza en la Edad Media, en torno a la ciudad mencionada, otrora un puerto. Dante canta a Flandes y a sus flamencos, los cuales (con cierta lógica que después veremos no es absoluta) también hablaban el flamenco. Sería un disparate equiparar los términos actuales con los de antes y excluir de ese elogio a muchísimos holandeses. Este territorio sufrió durante siglos la embestida expansionista francesa, por lo que quedó marcada la memoria del 11 de julio de 1302, actualmente día de Flandes, por la hatalla «de las espuelas de oro». Triunfaron los artesanos flamencos 
contra la caballería francesa, en lo que ha sido descrito como una especie de precursor de Dien-Bien-Phu. Siglos más tarde, el condado de Flandes se anexó a la Francia revolucionaria, para constituir parte sustancial de Bélgica, a partir de su independencia en 1830. Actualmente el «flamenco» se refiere a la expresión regional belga del neerlandés, con casi seis millones de personas, teniendo en cuenta en este conjunto gran parte de la población de Bruselas, actual capital administrativa de la Unión Europea.

Respecto de este punto, conviene enderezar dos entuertos: el primero, no existe ninguna relación probada con el cante jondo, expresión musical andaluza, pese a que, en buena ley globalizadora más de un flamenco toca guitarra; ello no quita que alguna puntita del velo se ha levantado ya, en cuanto a vínculo entre los dos nombres, pues Flandes formó parte de aquel legendario imperio hispánico «donde nunca se ponía el sol». Aparte de interpretaciones fantasiosas, algunos indicios hay entonces ${ }^{3}$, ciertamente remontándonos a la presencia de consejeros flamencos del Rey-emperador Carlos V, en España, además de la presencia en Flandes de los temibles tercios españoles, en tiempos de su hijo Felipe II.

\subsection{El holandés errante, sí... pero ¿cuál?}

Desde luego, el vocablo Holanda y el gentilicio (también nombre de idioma) holandés, tienen una historia común. Ahora se asocian espontáneamente con los habitantes y la lengua oficial de los Países Bajos. Pero los mismos lugareños de estas tierras, a través de siglos de equivocación (dar el nombre de la parte al todo), ya se habituaron al equívoco. Es parte del sello turístico del país de los molinos y de los tulipanes, estereotipos visuales que igual se podrían aplicar a

Ver entre otras la interpretación, clásica, pero poco convincente, de Fernando Díez, en su columna "Tribuna del idioma», del 3 de diciembre de 1995, en el diario costarricense La Nación. En otros ensayos, también me he referido al tema. Más particularmente en «Lectura 'flamenca' del "Burdel de las Pedrarias" ", ponencia para el $V^{\circ}$ Congreso Centroamericano de Historia, San Salvador, en Romaneske (Universidad de Lovaina), Bélgica, año xxvı, $\mathrm{n}^{\circ} 1,1^{\mathrm{er}}$ trimestre 2001, pp. 58-65. 
Flandes. Hasta los mismos servicios diplomáticos respectivos, a pesar de emplear papelería membretada con «Real Embajada de los Países Bajos», jamás van a rechazar correspondencia llegada a nombre de alguien en Utrecht, con la leyenda «Holanda». Esta denominación corresponde más bien a las partes del actual territorio costero al oeste de allí, con las importantes ciudades de Ámsterdam, Rótterdam y La Haya. Para complicar más el asunto, desde la federalización, solo en Bélgica ya existen dos provincias, alrededor de Bruselas, con el mismo nombre de Brabante: una de habla neerlandesa (flamenca) y otra de expresión francesa (valona).

En perspectiva actual, todo remonta al histórico Ducado que en tiempos de Carlos V cubría ciudades tan disímiles como Breda o 'sHertogenbosch (Bois-le-Duc), en los actuales Países Bajos, lo mismo que Lovaina y Amberes, en la actual Bélgica. Ahora bien, lo mismo que el primitivo flamenco Van Eyck, cuyo «Cordero Místico» todavía figura en Gante, en Flandes ( $40 \mathrm{~km}$ al este de Brujas) no lo fue menos por ir a trabajar varios años al norte, en lo que hoy muchos llaman «Holanda». Tampoco Pieter Bruegel el Viejo (1525/27-1569) puede ser calificado como «maestro holandés» como lo hace apresuradamente El País ${ }^{4}$. A estas alturas todavía hay dudas sobre su nacimiento en Breda (en el centro de los actuales Países Bajos) o en Amberes (el puerto, al norte de Bélgica), pero consta que su desempeño profesional gira esencialmente alrededor de esa ciudad y Bruselas. Al viejo Brueghel, como a pocos, le tocó vivir y sufrir el desgarramiento de su patria (literalmente: la tierra de sus padres), en dos pedazos irreconciliables por causas religiosas; de allí que el límite actual entre los Países Bajos y Bélgica tenga mucho todavía de separación por el credo que profesa su gente, calvinista versus católico.

Que el arte constituye un idioma universal es verdad de Perogrullo, al mismo tiempo que verdad a medias, porque tampoco la imagen se decodifica como pura y simple representación visual, sino

En artículo de S. Robla, del lunes 28 de mayo de 2001.

176 
a partir de un código común entre creador y espectadores. Por nuestra común cultura cristiana (una globalización de hace dos mil años), tanto en Centroamérica como en el norte europeo entendemos a Brueghel, pese a que no hablamos la misma lengua respecto de su famoso cuadro Los siete vicios (1557): los monjes franciscanos (varios flamencos ${ }^{5}$ ), contemporáneos del pintor, inculcaron en los indígenas el rechazo por ciertos pecados, con determinados nombres, agrupados en el mítico-occidental número de siete. A los nativos les pusieron anteojos estéticos y religiosos con sello europeo para ver parecido de un lado y otro del Atlántico. Pero el uso de la lengua siempre complica algo la percepción común: todo receptor puede admirar todavía el cuadro Refranes flamencos (1559) del mismo pintor, con su inherente plasticidad de expresión, su pincel fino y su caracterización de la gente sencilla, pero estoy seguro que los espectadores de Bélgica y de «Holanda» le sacan mucho más provecho, porque pueden leer los letreros con los refranes visualizados, en un doble código de refuerzo mutuo ${ }^{6}$.

Las fronteras reflejan cicatrices del pasado. En el siglo xv, lo demuestran tantas figuras ilustres, de importancia todavía grande también por acá, pero nacidos allá, a un lado u otro de esa barrera artificial: es el caso de Adriaan Boeyens, el futuro Papa Adriano, conocido como «de Utrecht» (al norte, en los Países Bajos actuales), preceptor de ese mozo llamado Carlos I de España (Carlos V de Habsburgo), nacido en Gante, educado entre Malinas y Oudenaarde (pujantes ciudades al sur de los históricos Países Bajos). Es el mismo caso también de Erasmo, «hijo del amor» en Rótterdam («Holanda»), pero docente en la flamante Universidad de Lovaina, donde fue colega del citado Adriano; eran compatriotas, no solo en la gran Patria eclesiástica

\footnotetext{
$5 \quad$ Pienso en Pedro de Gante. en México. Joost De Rycke y compañeros. en América Central, el primer obispo de La Habana. un tal De Witte, todos más conocido por la traducción u otras referencias a su origen flamenco. como Pedro de Gante y Albino.

6 En este contexto, y para mayor investigación queda por probar que los términos pancakes y waffles, ahora muy comunes en Centroamérica por influencia anglosajona, originalmente provienen del neerlandés, respectivamente pannekoeken y wafels, como elementos muy típicos en el panorama culinario flamenco y que se prestan al vicio de la gula.
} 
(la Iglesia Católica y Romana), sino en una especie de prefiguración del actual «Benelux» ${ }^{7}$ que eran los Países Bajos de los siglos xv y XVI. De allí que también el actual lector de «esas tierras bajas que son mías» (la frase es del cantautor belga Jacques Brel), al saborear el «elogio de la locura» de Erasmo, pueda disfrutar más que el paciente lector circumcaribeño. En efecto, pese a estar redactado en latín, la lengua universal de entonces, el texto de esa guasa-de-intelectual está salpicado de referencias al lenguaje popular, al idioma del hombre común en Flandes y en los Países Bajos. A como Unamuno aprendió danés, solo por entender mejor a Kierkegaard en el original, ¿deberemos recomendar a los centroamericanos dar una vueltita por los bares y lugares populares de por allá, todos de idioma común, para aprender a saborear en su salsa las metáforas que utiliza el querido Erasmo?

\subsection{El neerlandés, ¿lengua de los Países Bajos? Sí y no}

Corro voluntariamente el riesgo de marear al lector, con tanta referencia histórica y geográfica, pero la realidad identitaria va siempre más allá de separaciones artificiales de estado y de política. Simplificando un tanto, puede decirse que el legado del imperio Habsburgo en el norte europeo prefigura la actual región cultural e idiomática del neerlandés. Recién ahora va entonces la explicación respecto de este último término, tan manoseado y evolutivo como los otros en la presente agrupación de cuatro. El que maneja aunque someramente varias lenguas occidentales ya habrá percibido que, en realidad, el vocablo «neerlandés» (el idioma) se parece bastante al nombre de «País Bajo», dicho precisamente en neerlandés: «Nederland», refiriéndose a las legendarias tierras, algunas bajo el nivel del mar. Con lo cual, o bien se aumenta la confusión o bien se aclara que grandes partes de las actuales Bélgica y «Holanda» provienen de una misma raíz étnica y se expresan todavía con el vehículo linguiístico de ese grupo.

Toda comparación cojea; al tener que excluir de ese territorio común, en grandes líneas, el gran Ducado de Luxemburgo y el Principado de Lieja, pero a su vez añadiéndole partes del norte del actual norte de Francia: la ciudad de «Lille», por ejemplo, perteneció históricamente a Flandes. 
Esas regiones, tanto en la actual Bélgica como en «Holanda», tienen en común no solo condiciones físicas, sino también avatares históricos: los Habsburgos ${ }^{8}$ los consideraban como unidad: por eso, al abdicar el gran Carlos V, nacido en Gante, $30 \mathrm{~km}$ al este de Brujas, quiere que (pese a estar «lógicamente» $\mathrm{y}$ «geopolíticamente» asociadas a la futura Alemania, regida por su hermano), «sentimentalmente» pasen a Felipe, su propio hijo, para seguir juntas con la corona española. Lo mismo, después de la derrota de Napoleón en Waterloo (cerca de Bruselas), en 1815, otros grandes de entonces consideraban que esos territorios chicos se debían juntar (como ahora resulta fácil a los europeos recomendar la unión centroamericana). Pero las circunstancias también pueden dificultar esa «naturalidad» unitaria: en un proceso que tardó siglo y medio, los intereses entre los grandes bloques europeos, por un lado, así como la cizaña interna, llevaron a un divorcio ineludible entre los «Países Bajos del Norte» (prefigurando «Holanda») y los «Países Bajos del Sur» (prefigurando Bélgica). Como en todo, los motivos profundos fueron esencialmente económicos, pero entonces (lo mismo que hasta hace poco en Irlanda), la razón evidente que se esgrimió resultó ser religiosa.

Etapa crucial en esta ruptura fue sin duda la represión española, primero por el terrible Duque de Alba con su «pacificación» de Gante en 1576, con la ejecución de los gobernantes locales, en pleno Bruselas y el incendio de Amberes: todas ciudades actualmente belgas; después la represión también se ef ectuó a sangre y a fuego más arriba: piénsese en el famoso cuadro Las lanzas (es decir, La rendición de Breda, 1626), de Velásquez y a lo que alude también Lope de Vega. Todo ello generó una tremenda diáspora desde Flandes, sobre todo hacia el norte, peroigual hacia Alemania (como con los padres de Rubens y los de Vondel; es el caso, igual, de Mercator). La fuga de cerebros y de capitales desde la futura Bélgica hacia las tierras que a raíz de eso despegaron y se conocen ahora como las del holandés errante. Esta

$8 \quad$ Nuevamente, mutatis mutandis: los Países Bajos burgundios incluían no solo grosso modo los actuales Bélgica y «Holanda», sino también Artois y la actual «Flandria» (Flandes) francesa. 
división fue de funestas consecuencias funestas para los Países Bajos del sur, sobre todo con el bloqueo marítimo de Amberes, en 1585, lo que rompió el conjunto territorial en dos. No es un divorcio, sino que un elemento tercero, el español, se metió de por medio de manera tan torpe como fanática. En términos jurídicos este fraccionamiento fue dado como definitivo, en 1648, con el Tratado de Münster; en adelante el auge de los puertos nórdicos de Rótterdam y Ámsterdam. En términos lingüísticos aquí puede darse el origen del efror tan frecuente de considerar el «holandés» y el «flamenco» como idiomas diferentes, cuando en realidad se trata de gemelos separados a la fuerza.

Esa especie de «Vietnam» ${ }^{9}$ en que se enfrascaron los tercios españoles también provocó hondas repercusiones en la lengua y en la educación por ambos lados de la línea de ruptura. En ese último campo, por la sangría de profesores y la libertad docente, la Universidad de Lovaina tuvo que cederle el liderazgo a la de Leiden, que se fue rigiendo bajo el lema haec libertatis ergo (por la libertad), opuesto al religionis ergo del gobernador español, también conocido como Duque de Hierro. Finalmente se selló la ruptura: el nombre de «Países Bajos» se fue asociando cada vez más con el de la llamada «República de las Provincias Unidas» de 1648; en cambio, antes de conocerse como «Bélgica» el sur se llamaba «los Países Bajos Meridionales», primero «Españoles», hasta que en 1713, con el Tratado de Utrecht, los Países Bajos del Sur pasaron a ser «Austríacos», siempre en régimen monárquico-católico, solo que bajo el mando de otra rama de los Habsburgos. Para los del norte esos años de lucha implicaron un refuerzo identitario, entre otros mediante el idioma: de allí que en el himno de los actuales «Países Bajos» todavía se evoca a los españoles de una manera nada cariñosa. Hoy, seis millones de habitantes de Bélgica y quince millones de los Países Bajos cantan y hablan al unísono el neerlandés.

7) Retomo la metáfora de Juan Eslava Galán, quien en Historia de España contada para escépticos (Barcelona: Planeta, 1995), se refiere a «una especie de Vietnam español». 


\subsection{Los belgas de Bélgica no hablan «belga» ni en trabalenguas}

Este cuádruple enredo lexicográfico y semántico requiere una explicación más respecto de un último término: Bélgica. Ya Julio César, en el año 57, señala que «de todos esos pueblos, los más valientes son los belgas», algo que más de un ingenuo por allá todavía toma como un piropo, pero los limites territoriales de los dos grupos, el de antes y el de ahora, difieren sustancialmente. Después de pasar de los Habsburgos españoles a los austríacos y más tarde formar parte del imperio napoleónico, el país de ese nombre recién fue presentado en la fuente bautismal en 1830, formalizando también la separación de un matrimonio forzado con los Países Bajos. En un territorio intrínsecamente bilingüe eso había llevado consigo que las autoridades del norte impusieran la «neerlandización» administrativa (una injusticia para casi la mitad de la población que tenía como idioma materno el francés). Apenas a los quince años, con la independencia, ocurre lo contrario con el «afrancesamiento», otra iniquidad para la masa mayoritariamente de habla neerlandesa.

En realidad, flaco favor se hace, dentro del país, al identificar el neerlandés como flamenco, arraigada costumbre en bocas francófonas, como para disminuir la importancia de ese idioma de cuerpo entero (como si, por de pronto, un idioma adquiriera carta de ciudadanía por la cantidad de gente que lo habla); ¿qué tal si, sobre la misma base, los flamencos identificaran despreciativamente el francés del sur de Bélgica como «valón», un supuesto idioma aparte del que se habla en París? Pero fuera del país también, al no llamar las cosas por su nombre -y éste que lo pongan los especialistas en el caso, es decir los filólogos - tampoco favorecen la correcta comprensión los que, en este caso más por ignorancia, siguen distinguiendo entre el flamenco y el holandés, sin utilizar el vocablo apropiado: el neerlandés, la cilialiı «lengua de más de veinte millones de neerlandeses y flamencos».

Como en todo este ensayo, pongámoslo en paralelo centriallil. ricano: distinguir incorrectamente entre «holandés» y “liımı・ı॥... sería como proclamar de manera insensata que a lin ladlo y illu d l. 
Río San Juan se hablaran dos lenguas. Como si el nicaragüense y el costarricense necesitaran diccionario o intérprete para establecer la comunicación entre los ciudadanos de ambos países. No se trata entonces de dos idiomas independientes sino, a lo sumo, de variantes regionales del mismo español o castellano. Claro que de un lado de la barrera siempre se opina que «del otro» se habla «raro» y hasta «mal». Que no correspondan unas pocas palabras no son sino lindos matices dialectales que evitan que la lengua de Cervantes sea una camisa de fuerza, cortada y coloreada únicamente por ilustres catedráticos de Madrid. Exactamente igual, el flamenco y el holandés son florcitas mellizas sobre un mismo tallo. Una misma gramática, una idéntica sintaxis, una sola ortografía, todo con ligeras variaciones lexicográficas y de musicalidad al hablar. Pero la ignorancia y la distancia (uno favoreciendo lo otro) lleva a trampitas: no es cosa de hilar fino o ser majadero, porque puede haber muchos intereses de por medio. Incluso en la muy destacada Dirección Jurídica del Ministerio de Relaciones Exteriores, de Costa Rica, prevaleció hasta hace poco la separación artificial entre «holandés» y «flamenco», cosa que desde luego afecta al traductor oficial de «neerlandés». Conviene fijarse y hablar con corrección. Lo mismo pasa con el alemán, que en inglés se llama «German», a no confundir con el «Dutch» (término que se parece a «Duitsland», es decir «el país de los alemanes»), que en inglés significa «neerlandés».

No tiene sentido, sobre todo ahora considerando la globalización, seguir asociando ingenuamente los nombres de lenguas con los de países: graves errores conlleva ese simplista razonamiento al aplicarlo, por ejemplo, a Alemania o en el caso de Gran Bretaña; si hasta la muy nacionalista y centralista Francia del General de Gaulle tuvo que reconocer lo dañino que ha sido y resulta la confusión entre lo francés (refiriéndose al «hexágono galo») y lo francófono (esto último implica una dimensión distinta, en lo cultural, al mismo tiempo que más amplia, incluidas producciones en francés en partes tan distantes como África, Bélgica, Canadá y Suiza, entre otros). Pero por 
una ignorancia que no deja de estilar prejuicio y perjuicio, no es raro encontrar a gente que en su misma pregunta parece tener necesidad de repetir una falsa generalización desde su propio contexto: lo mismo que tampoco los costarricenses hablan un «idioma» costarricense (pero sí una variante tica del español), no tiene sentido suponer que al otro lado del Atlántico los belgas hablen belga.

No deja de ser curioso el caso, pues por lo general, a nadie se le ocurre afirmar que los austríacos hablan austriaco. No confundamos entonces gentilicio, nombre de país, con el nombre de un idioma, aunque a veces coincidan o se parezcan. Constituyen un trípode de términos relacionados en cierto sentido, pero intrínsecamente diferentes. El primero alude a ciertos habitantes en una determinada colectividad política; el segundo refleja esa misma idea de grupo organizado, también conocida como estado o nación, cada una con una etiqueta específica; por último, la lengua es el vehículo comunicativo-verbal de determinado grupo humano dentro o más allá de lo anterior, pero que para nada debe coincidir. En el caso belga, unos seis millones de belgas de pasaporte viven en Bélgica, constituyendo el $60 \%$ de su población; en el caso de los Países Bajos, unos quince millones de neerlandeses viven en su comunidad nacional, pero ambos grupos, conformando los millones citados de flamencos y neerlandeses, respectivamente, viven, piensan y aman en neerlandés. La historia separó a esos dos pueblos, que crecieron juntos durante siglos, pero ahora el contexto europeo e internacional (comotambién desdedentro, la voluntad constructiva), produjo en 1980 la Unión linguística («Taalunie»), para evitar fisuras y diferenciación entre los dos bloques regionales.

\subsection{Conclusión primera}

No es éste el lugar para desarrollar esta tesis, pero paralelo a la misma globalización, en todas partes, igual en el área circumcaribe como en el norte europeo, vuelve el interés por lo local, regionalpequeño, sostenido por la lengua, la etnia. Los Habsburgos, los Borbones y lo napoleónico (creadores, los tres, de estados desde 
arriba) han terminado. Una lengua tiene dignidad no por la cantidad de sus hablantes sino por constituir un sistema diferenciado de captación del mundo. El «flamenco» y el «holandés» constituyen variantes regionales de un mismo código expresivo. A éste, desde luego se puede aplicar la frase de George Bernard Shaw respecto del inglés, en versiones norteamericana versus insular, las cuales se separan únicamente por el mismo idioma. El neerlandés es la lengua de neerlandeses y flamencos; juntos pero no revueltos políticamente y contribuyen desde hace más de diez siglos a una polifonía cultural e idiomática.

\section{Segunda parte: puentes curiosos con el español y el área «cir- cumcaribe»}

\subsection{Lengua y racismo cultural}

Sobran los apocalípticos, asustados por el fin de la diversidad cultural e idiomática a causa de la tecnología; pero ésta, dentro de la misma globalización, a su vez ha sido motor principalísimo del rescate o conocimiento de esas múltiples formas de expresión. Bien entendida, también puede llevar a salvaguardar y construir el mosaico, artístico o no, verbal o no. Desde una perspectiva histórica y filológica, ya he ubicado el neerlandés, esa lengua de la que hasta el nombre parece enredado. Lo hice a partir de la aclaración semántica de cuatro conceptos difíciles de entender fuera de su contexto de origen. Ahora ahondaré en ello desde la dimensión más bien cultural del mismo idioma, mostrando tanto la potencial riqueza universal de la literatura en neerlandés, como ciertos puentes con el español, todo con la idea de continuar situando ese idioma en el concierto mundial.

En el área «circumcaribe», como la he llamado, existe cierta valoración para muchos elementos de la cultura europea y, respecto de los idiomas, hasta afloran resquicios del prejuicio casi racista que un gran escritor de los históricos «Países Bajos» ha divulgado: Mauricio Maeterlinck, Nobel de Literatura en 1911, muy celebrado por aquí sobre todo por las preciosas traducciones de Roberto Brenes Mesén, 
entre otroas de El pájaro azul. ${ }^{10}$ En una de las curiosas complejidades de su región de origen, de habla neerlandesa, este autor escribía en francés y tuvo respecto de esta lengua de su apellido la poco afortunada expresión de que se trata de «una jerga cenagosa» ${ }^{11}$. Es como Charles Péguy, su compañero de filas, quien orgullosamente declaraba que no había leído nada fuera de lo producido en su idioma, el francés. Pobre chauvinista; desde este lado de la barrera, Carlos Fuentes les contestaría que «el monolingüismo es una enfermedad curable». Al inicio de un siglo que promete ser más tolerante ( $₫ a$ lo mejor apenas menos intolerante?) y en el año europeo de las lenguas es conveniente entonces, también por este lado del Atlántico, favorecer la pluralidad de todo tipo, evitando ese tipo de racismo cultural aludido.

\subsection{Literatura y visión de mundo}

No existe arte "pequeño», como tampoco excelencia (ni mediocridad) a medias. En el área de habla neerlandesa, pese al tamaño reducido de su superficie gestadora, hubo grandes artistas también: basta pensar en los «primitivos» flamencos y en diversos creadores de música polifónica. Sin embargo, los productores de arte verbal en contextos reducidos, sobre todo por la lengua «minoritaria» que manejan, tienen la dificultad de trascender al plano internacional. Al respecto, tengo para mí que el último premio Nobel de Literatura, un chino (sustancialmente desconocido en Occidente antes de ese galardón), por lo menos todavía lleva ventaja sobre sus colegas de lengua neerlandesa, la que hablan «solo» en los Países Bajos y el norte de Bélgica. A continuación ubicaré tres autores de ese ámbito cultural e

$\overline{10}$ Recientes publicaciones. como Brenes Mesén: el caballero de la enseria escarlata, de Faustino Chamorro (Heredia: Editorial Universidad Nacional, 2000), o La ciudad de los monos, de Iván Molina (coedición entre Editorial Universidad Nacional y Editorial de la Universidad de Costa Rica, 2001) realzan la figura de Roberto Brenes Mesén. Queda pendiente un estudio, al que me comprometo, sin fecha, en relación con los múltiples puentes entre este educador y Bélgica. especialmente en el plano pedagógico y como traductor.

11 La poco af ortunada frase la habría publicado en el periódico Le Figaro de los años 1900, sc gún J. Goosenaerts, en Ons Nederlands, un jargon vaseur? (Langemark, Bélgica: Ed. Vonkstecen. 1958): según otras versiones, el Cardenal Mercier tendría la autoría de ese ex abrupto. 
idiomático. Constituyen apenas una muestra, cosa de sensibilizar para su inherente visión de mundo; de allí, confío, se valorará además de lo difícil, lo necesario que sería traducirlos al español igual que a varios idiomas de mayor alcance.

Joost van den Vondel (1587-1679) es el poeta y dramaturgo «fundador» para la dignidad literaria en neerlandés. No es, ni mucho menos, que esta lengua, vieja entonces ya de setecientos años, no hubiera dado antes, por ejemplo en la Edad Media, obras de peso ${ }^{12}$, pero la grandeza del artista del siglo XVII contribuyó, sin duda, a la dignidad del Estado delos Países Bajos, como realidad independiente. La fuerza cohesionante del idioma ayudó a ello y para eso el autor sobresale primero como importante traductor del francés y de lenguas clásicas hacia el neerlandés. Recalco la identificación entre el hombre y su nación, en este caso, porque no por casualidad, el primer poema de Vondel es un gran himno a la navegación: estaba naciendo el imperio colonial holandés. Sin embargo, al autor tampoco se le puede adscribir un tono nacionalista, porque su temática suele ser de otra índole. Es por esencia humanista y religiosa, haciendo que se rebelara contra el estricto calvinismo que se fue imponiendo en su tierra mientras, en cambio, él se convirtió al catolicismo, la religión de los enemigos, en el sur, los Países Bajos Meridionales (la futura Bélgica) bajo la bota española. Su primera obra La Pascua (Het Pascha, 1621), lo mismo que sus poemas iniciales fueron el resultado de su estudio sobre el drama clásico. Sus adaptaciones de la tragedia griega constituyen obras maestras del arte barroco, todo dentro de la búsqueda de la fe. Además, escribió una serie de dramas originales, como Jerusalén destruida (Hierusalem verwoest, 1620) y la trilogía Lucifer (1654), la cual influyó en John Milton. También está Adán en el exilio (1664) y Noah (1667). Existen algunas traducciones al inglés, pero por lo

$12 \quad$ Pienso en Halewijn y Reinaen de Vos, leyendas medievales que tuvieron en los antiguos Países Ba jos diversas repercusiones literarias, aparte de alcance verdaderamente europeo. El primer caso incluso de jó bases para el mito-espectáculo comercial de Halloveen en Estados Unidos. en una versión totalmente transformada. 
general, su obra, más que en el olvido, queda en el desconocimiento, fuera de suárea original de creación. Lástima: por vocación, la obra de arte está para comunicarse.

Un segundo autor importante, digno de rescate a escala universal, dentro de la literatura de habla neerlandesa es Eduard Douwes Dekker (1820-1887), más conocido por su seudónimo Multatuli. Su obra clásica, Max Havelaar, escrita en Bruselas en 1859, contiene una violenta denuncia del sistema colonial de su propiagenteen Indonesia, concretamente en Java. Por sus recursos de reiteración y de imagen, algo tiene del soplo épico de las grandes obras fundacionales en varias literaturas. Existe felizmente una traducción de esa obra, al inglés (en Penguin Classics, 1987) que por lo menos ya para ese público mantiene vivo el grito de rebeldía tan actual, pese a los casi ciento cincuenta años de los eventos denunciados. En otro escrito he relacionado esta producción con la del nicaragüense Azarías Pallais ${ }^{13}$ y en Centroamérica funciona una asociación de productores de café con ese nombre ${ }^{14}$, signo de que se identifica el escrito original dentro de la perenne lucha por la dignidad del trabajador en contra de cualquier explotación. Para la literatura neerlandesa Max Havelaar es el equivalente de Mamita Yunai, en la literatura costarricense.

Espero no caer en un pecado capital a la hora de la globalización, al afirmar que, de no haber escrito en neerlandés, Stijn Streuvels habría podido obtener el Nobel. Este autor, de nombre Frank Lateur (18711934), e n El otoño evoca con el mismo soplo épico tanto las poderosas fuerzas naturales como el alma de la gente rural en Flandes. Pero con la que realmente se destaca como naturalista es en El campo de lino (De vlaschaard, de 1907). Se trata de una obra que no solo pone sobre

\footnotetext{
13 Ver «Azarías Pallais: cuatro entronques sorprendentes (con énf asis en la relación con Bélgica)», artículo por publicarse en la revista Romaneske (Bélgica).

En Centroamérica funciona una cooperativa de productores de café, reunidos por la mística que generó Max Havelaar. (Originalmente llevaba incluso ese nombre; se trata ahora de la «Fairtrade Labelling Organizations» (FLO), cuyo «Monitor» actual para la región es el belga Guillermo Denaux, con sede en San Salvador.) En Bélgica, Suiza, Francia, Dinamarca y Noruega funcionan organizaciones bajo el nombre de Havelaar.
} 
el tapete el valor simbólico-cultural del lino en el sur de Flandes, sino que escenifica de manera trágica la lucha generacional entre un viejo padre y su hijo inconforme. Dewey, crítico holandés, señaló al respecto que si el sol pudiera escribir, lo haría parecido a Streuvels, viendo la tierra desde lo alto, en su conjunto y antes de que empezara parecería comprobar que todo tiene su sitio. El artista se vuelve demiurgo, construyendo y reconstruyendo el alma con el entorno de su gente; pero en la descripción tan sensible, sutil y profunda a la vez, toca el alma universal. Se dirá que ese escritor copia a Zola, pero se trata de una apropiación y reinterpretación tan lograda como difícil de ser proyectada fuera de su ámbito lingüístico, precisamente por lo cuantitativamente limitado de éste.

Ojalá la globalización lo sea también en lo cultural, bien entendida como diálogo en dos sentidos. Que lo cultural adopte entonces la idea medular de la internet originalmente militar: una estructura sin centro donde toda la información se puede generar desde todos los puntos y llegar a cualquier parte. Maravilla sería que la literatura regional centroamericana se pudiera dar a conocer en los países de habla neerlandesa, lo mismo que a la inversa. Un ejemplo local: que Fabián Dobles y sus Historias de Tata Mundo se conozcan en Londres, lo mismo que nosotros conocemos a los personajes populares de Dickens $^{15}$. Que ambos autores se conozcan en los Países Bajos y que la producción de allá se valore también acá. «Sueños hay que verdad son» proclamaba Calderón de la Barca. ¿Será posible también con lo artístico? Más allá de barreras idiomáticas, se descubriría que en las letras nicaragüenses hubo un Azarías Pallais, como en las de habla neerlandesa vivió el sacerdote-poeta Guido Gezelle ${ }^{16}$. Existe un alma humana, una sola, con más de 6.000 millones de variedades expresivas.

is El libro de Dobles felizmente ha sido traducido al inglés por la Editorial de la Universidad de Costa Rica: lo mismo se puede decir de los relatos de Quince Duncan. En defensa de la misma tesis, ver mi artículo «Globalización literaria bien entendida», en La Nación, suplemento Ancora, 25 de abril de 1999.

16 Ver tanto el artículo ref erido en la nota 4, comootro, también mío: «¿Un pasaporte flamenco para Azarías H. Pallais?», en Mélanges Nachtergaele (Bélgica), 2001. 


\subsection{Enlaces curiosos con el español (y lo universal). Énfasis en América Central}

Lo que sigue se debe a raíz de sorprendentes coincidencias históricas, como que los antiguos «Países Bajos», lo mismo que las colonias españolas, estuvieron casi dos siglos (empezando en 1517, con el flamenco Carlos V), bajo un mismo Jefe de Estado ${ }^{17}$. Es vinculación forzada, de política dinástica, pero su duración e intensidad dejaron desde luego huellas por ambos lados. Sin ánimo de ser exhaustivo porque por de pronto desviaría el eje central de este trabajo, sugiero someramente cuatro tipos de interferencias complementarias entre las dos comunidades lingüísticas en cuestión. Todo desde luego repercute finalmente en el plano mundial, como veremos.

\subsection{Influencia del español en neerlandés}

Como en la mayoría de las lenguas occidentales, en neerlandés penetraron vocablos indígenas americanos mediante el español: es el caso de petaten, dialectal para papas. Lo mismo ocurrió con otros alimentos de origen indígena, como con los equivalentes por allá, de tomate, chocolate, cacao y maíz. A lo anterior cabe añadir términos para prácticas o realidades del mismo origen antropológico como tabaco, canoa, hamaca, caníbal, tornado y barbacoa, que se explican por sí mismos, importados varios de ellos en neerlandés y en ruso. Además, por lo menos una expresión refleja un contacto directo entre el español y el neerlandés. La palabra furie (furia) en neerlandés, podría provenir del francés, pero en la combinación Spaanse furie (furia española) dejó una huella que parece indeleble: todavía para las madres y los niños de los históricos Países Bajos, a casi quinientos años de los hechos, el Duque de Alba es como aquí, el mismo «cuco».

$17 \quad$ Ver dos de mis artículos: «Carlos V de Flandes y su peculiar vivencia de las lenguas (lecciones del Siglo X'ı. a la hora de otra mundialización idiomática)», en Romaneske, Universidad de Lovaina, Bélgica. $4^{\circ}$ trim. 2000, pp. 41-50; y «De cuando un flamenco era Jef e de Estado en Costa Rica...", en el Suplemento cultural del periódico Campus (Universidad Nacional), 2001. 
A continuación van también unas muestras en el mismo sentido y de la misma época, en palabras aisladas: en neerlandés coloquial, a los habitantes de Amberes se les llama Sinjoren, con evidente resonancia castellana de «señores»; otro ejemplo: si en Bruselas existe ahora un hotel de cinco estrellas, de nombre «Amigo», no es solo porque el establecimiento, para decirlo con un calco del inglés es «amigable», sino porque allí, en tiempos de la ocupación hispana había una cárcel, lugar desde luego nada user-friendly. La relación se debe a que los españoles practicaron muchísimas arbitrariedades, incluso al hablar a los detenidos en idioma ajeno. En neerlandés de entonces la palabra amigo llegó a ser, en la mente de gente que no hablaba el idioma del opresor, una especie de equivalente de «retén de policía» o lugar de detención provisional porque los soldados, de manera poco amistosa en realidad, en el momento de detener a alguien y llevarlo preso le decían «vamos, amigo». Muchas veces las evoluciones lingüísticas obedecen a todomenos a la racionalidad ${ }^{18}$. Por eso, en ciertos dialectos del sur, en la zona «neerlando-hablante», la muletilla que correspondería al «este», o en costarricense «o sea» es entongs, partícula que no requiere experiencia filológica para asociarla al «entonces» hispano.

\subsection{Influencia del neerlandés en el español}

En el sentido inverso, también conviene trazar una pincelada respecto del impacto lexicográfico del idioma de Vondel en el de Cervantes. Se trata de muy escasas palabras, originadas además en campos semánticos heterogéneos. Igualmente en lo alimenticio, concretamente pesquero, del Atlántico norte, los españoles importaron el arenque y el bacalao junto con sus referentes neerlandeses haring y kabeljouw, respectivamente clupea harengus y gadus morrhua, en latín; de allí las expresiones figurativas como «es un bacalao», por lo

is Por cierto, hablando de irracionalidad, lo mismo pasa al otro lado de la frontera lingüística en Bélgica: igual en francés, en este caso en el dialecto «valón», el término muy hispano de «amigo» tiene una resonancia no precisamente amistosa, sino como «cárcel», casi idéntica a la acepción del término en neerlandés regional. 
flaco y lo prensado de la presentación (curiosamente con equivalentes en neerlandés, pero más bien a base del otro pescado mencionado). También, en español: «cortar el bacalao», figurativo y familiar por «tener la superioridad o dominio en alguna cosa» (Casares).

Otra esfera de actividad interfirió entre pueblos tan diferentes y distantes: es lo militar. Lo que ahora se conoce como un «bulevar», en el sentido de calle ancha, generalmente con árboles a ambos lados (según Casares) originalmente proviene de bolwerk, es decir de un trabajo (werk) de fortificación en redondo (bol), alrededor de la ciudad, los muros amplios que rodeaban el «burgo» medieval (en España, el caso de Ávila). Después, esta estructura fue utilizada como vía de circunvalación: así también pasó al inglés y al francés (recuérdese los famosos trabajos de Hausmann en París). En español moderno, el bulevar es sinónimo de avenida, tal como ocurre también en varios idiomas occidentales: se hace hincapié en lo ancho de la calzada, porque muchas veces, como en avenue o boulevard norteamericanos, los árboles han sido eliminados para dar aun más espacio a los vehículos automotores. En Costa Rica el término se utiliza más como «paseo peatonal».

Queda dicho: los españoles se metieron en un verdadero avispero en Flandes. Dos expresiones refieren a esa misma idea de lo grande y riesgoso: «poder pasar por las picas de Flandes» es una figura con que se pondera que una cosa tiene toda su perfección y excelencia; paralelo a lo anterior está: «poner una pica en Flandes», expresión figurada y familiar para «conseguir una cosa muy difícil», siempre según Casares. Los grandes autores del Siglo de Oro, como Lope de Vega y Calderón de la Barca, tienen reminiscencias a Flandes y la faena española por allí. El primero, por ejemplo con $\mathrm{El}$ sitio de Mastrique, la actual Maastricht; el segundo, por lo que sabemos de su biografía, estuvo en Flandes. Por cierto, ganarse la lotería es otra actividad tremendamente difícil, con incidencia de la diosa fortuna. Pues ha de saber el lector que las palabras lot y loterij, respectivamente «(buena o mala) suerte» y un sistema de designación por el azar, 
provienen del neerlandés. Este sistema muy en boga, ahora se conoce más para la atribución fortuita de premios, pero durante siglos estuvo legitimado también para labores, por ejemplo para la conscripción militar. Lo cierto es que el inglés, el ruso y el alemán, entre otros, testimonian todavía de esa práctica del sorteo, generalizada en Flandes en tiempos de Carlos V. No será por casualidad que un tipo de imprenta especial, los naipes, concretamente por una fábrica de Turnhout entonces, durante siglos mantuvo renombre internacional. Ya en 1532, la palabra lotterie se conoce en francés y en otros idiomas occidentales.

Un último caso de interferencia del neerlandés en el español es la kermese. Es la verbena o fiesta popular, benéfica con rifas, etc., originalmente kerkmis. Por sus componentes $($ kerk = iglesia; mis = misa), ahora por aquí entendemos el asunto como fiestas patronales, en las ciudades, pero de carácter eminentemente rural-popular, de tipo anual y con grandes diversiones. Aparte de los apuros que vivieron en esas tierras, es probable que los invasores también envidiaran la manera de divertirse delas poblaciones bajo su dominio. El término va preferentemente relacionado con Flandes, la parte sur de los Países Bajos históricos y en el compuesto de «kermese flamenca» evoca hasta el título de una película; también espontáneamente evoca a Brueghel. De 1559 hay dos grabados suyos, ambos escenificando prácticas aldeanas en Hoboken, en la cercanía de Amberes. Ahora bien, en los dos se observa esencialmente la misma idea que da origen al término: como se acostumbraba en los pueblos coloniales (en Costa Rica: en Ujarrás y Orosi por ejemplo) el cementerio rodea el templo, pero la diferencia entre la mente hispana y la flamenca, ésta última muy evidenciada también en El Bosco (pintor flamenco más conocido con su nombre vuelto al español), es que los cementerios no se consideraban lugares que invitaran al recogimiento. Al contrario, se observa toda clase de diversiones populares, bailes y actividades jocosas, nada más al salir de la iglesia. 


\subsection{Interferencias específicas del neerlandés en la zona «cir- cumcaribe»}

Dos muestras se rastrean, con clara incidencia de Flandes en toponimia de este lado del Atlántico. El primero es el caso de lo que tendríamos tendencia a llamar «Bruselas de Costa Rica», si no fuera porque este país, como tal no existía todavía. Era el inicio de la colonización española en el istmo, recién después del descubrimiento del Pacífico. Explorando a partir de lo que ahora es Panamá, Pedrarias Dávila mandó crear tres asentamientos todos en 1524, primero León y Granada (en la Nicaragua actual) y después la «Villa de Bruselas» (probablemente entre Puntarenas y Cañas, ahora de Costa Rica). Los dos primeros nombres tienen evidente reminiscencia hispana, mientras que el último se puso en honor al Emperador de entonces: el citado flamenco Carlos V. Sin embargo, debido a las luchas entre conquistadores, ya en 1527 se mandó despoblar ese pueblo. El nombre es de clara resonancia neerlandesa, al observar que también el original Brucsela, terreno fangoso, tiene un parte inicial que, como sufijo, aparece en varios topónimos de Flandes y de Holanda (Willebroek, Melsbroek, entre otros) ${ }^{19}$. El segundo caso sorprendente es que, de repente, en Panamá se encuentra una isla con el nombre de «Flamenco»: se trata de otro recuerdo de casi medio milenio dedicado al Jefe de estado de entonces, en cuyo imperio, literalmente, «no se ponía el sol».

Pero hablando de fantasía, también se rastrean ciertas reminiscencias «flamencas» en tierras centroamericanas, que a veces resultan dudosas en aquel istmo que por algo se llamó originalmente «Estrecho dudoso». En Costa Rica por ejemplo, a una persona muy flaca, antes sobre todo, se le decía «flamenca». Consta desde luego la presencia de más de un individuo del pueblo flamenco en los primeros años de la Conquista $^{20}$, pero el asunto parece remitir más bien al término homónimo

19 El término es netamente germánico, al encontrarse por ejemplo también en el alemán de Innsbruck y hasta en topónimos en inglés (Pembroke y otros).

Ver Peter Boyd-Bowman, Índice geográfico de cuarenta mil pobladores españoles de América en el Siglo XVI (Bogotá, 1964), volumen 1.. De esos primeros «españoles» de América en el Siglo xvi", según algunas investigaciones, unos dos mil serían «belgas» y más particularmente «flamencos», con nombres hispanizados. 
de ciertas aves de patas muy largas; a saber también si el apellido del heroico educador salvadoreño, víctima de la dictadura de los Tinoco, en Costa Rica, de nombre García Flamenco, no tiene a la larga algún nexo con Flandes; los hechos a veces son más sorprendentes que la misma imaginación.

\subsection{Conclusión segunda}

Se ha precisado otro poco la pregunta inicial acerca de ese idioma que algunos se empeñan en llamar neerlandés. ¡Es tan rico aprender lenguas de otra parte, porque cada una es como una ventana que se abre! Cada idioma of rece, con un poco de esfuerzo, como en todo encuentro que valga la pena, una cantidad de trampitas inherentes, por la diferente visión de mundo que hay detrás, pero también de gratas sorpresas, de curiosas interferencias y a veces de identificación profunda, con mayor razón si el conocimiento idiomático es el trampolín para conocer su respectiva literatura. El neerlandés es un mundo a su alcance.

\section{Tercera parte: pasado, presente y futuro en contexto global, para el neerlandés}

\subsection{Entre primos, en busca del abuelo en común}

Que el neerlandés no es «como chino», al decir de alguno, tampoco «una versión dialectal del francés», según el ojo poco avisado de otro, se hace patente al hacer una especie de radiografía del idioma como tal. No sorprende que en el siglo XVI, con el poco cariñoso «encuentro de dos mundos», en varias partes se efectuó una confrontación de los vehículos expresivos y volvió la pregunta sobre la lengua más vieja, con la «lógica» de hacer remontar todas a una sola. En ese entonces surge una interpretación retomada nada menos que en la Enciclopedia Católica (Katholieke Encyclopedie): Adán y Eva, en el Paraíso terrenal hablaban neerlandés, siendo que según cierta etimología, por lo menos cuestionada, el nombre de la lengua duyts (sinónimo que en 
inglés da Dutch) puede leerse como «la más vieja» (de oudste, sobre todo si se pronuncia según la versión dialectal de Amberes ${ }^{21}$ ). Ello no deja de tener su repercusión también en lo pictórico: basta ver la Torre de Babel, en cualquier versión de Brueghel, como para que éste levante esa mole en ese mismo puerto.

Siendo raro el caso que nos ocupa, resulta más seguro partir de un tronco común indo-europeo de lenguas, con una separación en tres ramas principales: las germánicas, las románicas y las eslavas. Del último grupo dan testimonio todavía el ruso y afines; del segundo, todos los idiomas (el francés, el español, portugués e italiano, entre otros) que descienden del latín o romano; por último, del tercer bloque dan cuenta específicamente las lenguas escandinavas, el inglés, el alemán así como el neerlandés. Los filólogos concuerdan en situar en el siglo viII de nuestra era el nacimiento de ese vehículo comunicativo, pero habría que esperar el XII para una primera muestra escrita: un poema ingenuo, amoroso, poético, el cual, en traducción señala:

Todos los pájaros empezaron a hacer sus nidos excepto tú y yo, ¿qué esperamos por ahora?

En la Edad Media, como se vio, hubo momentos de trascendencia, por ejemplo con Halewijn y Reinaert de Vos, leyendas que tuvieron en los antiguos Países Bajos diversas repercusiones literarias, aparte de su alcance verdaderamente europeo y universal ${ }^{22}$. Pero también se ha señalado que hubo que esperar a Vondel, en el siglo XVI, para consagrar en forma artística la lengua neerlandesa.

Lo que se acaba de visualizar para la literatura, un crecimiento y una dignificación como entidad aparte, lo es además para su soporte, el

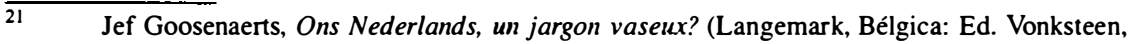
1958).

22 El primer caso incluso de jó bases para el mito-espectáculo comercial de Halloween en Estados Unidos, en una versión totalmente transformada.
} 
idioma como tal. No tiene sentido ver en la lengua neerlandesa un pariente pobre del alemán, o, peor aun, una heterogénea mezcla entre éste y el francés. Tal percepción obedece al desconocimiento sobre lo que es una lengua: más allá de un montón de palabras (lo léxico), se yergue como estructura independiente también en lo semántico, lo fonológico y lo sintáctico. Por ejemplo, con un oído atento en neerlandés, es posible captar bastante de una película de Bergman, en sueco, decodificando entre lenguas que se reconocen por un aire de familia y se parecen como primos, por remontar a idénticos y lejanos progenitores. Es verdad que con el alemán emparienta más el neerlandés, pero cometerá gran torpeza quien, más allá de moldes parecidos o hasta idénticos, confía que tanto en vocabulario como en construcción podría partir de una de esas lenguas para desembocar fijo y seguro en la otra. Los nietos se parecen, por fuera, pero se enojan si uno los confunde, porque quieren que uno los trate como adultos independientes que son o llegarán a ser.

El grado de parentesco directamente palpable es menor con el inglés, por una razón de distanciamiento físico (Inglaterra es una isla) y porque este idioma, apenas configurándose, en el siglo XII recibió una sustancial inyección francesa. Nadie lo consideraría bastardo por eso; al contrario, de allí arranca su riqueza. Lo anterior entierra el ingenuo pensar según el cual existiría una lengua químicamente pura; otra cosa es adquirir sensibilidad por cada lengua como sistema en sí, pero dinámico: por definición son como la piel, membranas con ósmosis, unidades que viven como tales, independientes, pero sensibles a influencias externas, las cuales absorben selectivamente y con base en su propia identidad. Afirmar o buscar lo contrario, temer por la confrontación de idiomas, equivale a postular tendencias que van desde el romanticismo al fascismo. El neerlandés, lo mismo que cualquier lengua, vive hoy bajo tremenda presión, entre otros del inglés, pero sería tan absurdo el rechazo de lo foráneo porque sí, como proclamar el advenimiento de no sé que «interlengua», pronto, con base en una mezcla de varias. A la hora de la globalización, que nadie 
clame al cielo en nombre de una pureza lingüística inexistente, utópica; lo mismo que es indeseable que el inglés de aeropuertos y de comida rápida se transforme en «el» idioma universal: en términos paralelos, el latín medieval finalmente cedió ante un mosaico expresivo, connotativo, real: las lenguas son organismos reales, con una dinámica propia. Conciencia lingüística es lo que se impone, en cada una.

\subsection{Globalización y diversidad lingüística: casos relacionados con el neerlandés \\ El pasado del neerlandés queda someramente explicado; antes} de pasar a ver su futuro, especialmente en el contexto europeo, quiero referirme a dos asuntos más, del presente, con su candente actualidad. El primero, que la importancia de las lenguas depende de la vara con que se mide (2.1); el segundo, que de este idioma tan pequeño constan varios casos más que sorprendentes con impacto que podríamos llamar «global» (2.2).

\section{1 «Idioma: ¿con qué vara comparar el neerlandés y el español?}

«Todo depende del cristal con que se mire» es una aseveración aplicable también al campo de las lenguas, con su peso relativo. Acostumbrados como están en todo el área «circumcaribe» al monolingüismo y al español como lengua si no única, en todo caso oficial y predominante, a los hispanohablantes les cuesta imaginarse siquiera países con varios idiomas vehiculares y hay quienes se preguntan, alarmados como Darío, si pronto «tantos millones de hombres hablaremos inglés». Sí, esos y más hablaremos inglés y ojalá además otras lenguas, pero sin olvidar la lengua materna. Desde luego y con mayor fuerza que antes, desaparecerán lenguas «minoritarias», pero en muchos casos no será «culpa» de Bill Gates y asociados, sino de la falta de cohesión y de conciencia interna del grupo minoritario.

En el contexto regional y continental, se hace supuestamente evidente esa amenaza externa, pero en el fondo se trata de falta de confianza interna y poco manejo del roce idiomático: es la nefasta 
mirada única. Del Río Bravo hacia el sur, pareciera que se ignora «o pais mais grande do mundo». Aparte de unas menciones folclóricas (con el fútbol, por el carnaval y la telenovela), el portugués «brasileiro» se pasa por alto: desconocimiento de la riqueza, en todo sentido que puede aportar precisamente lo polifónico en el aspecto tanto lingüístico como cultural. Otra situación excepcional, digna de estudio, la constituyen Guatemala y otros países pequeños en el «Mar nuestro» tropical. Lo anterior desemboca precisamente en el tercer caso, totalmente minoritario pero real, del neerlandés en América Latina, con restos del imperio colonial de los Países Bajos en el Caribe sur, como Aruba, Sint-Maarten y Curaçao. Se trata de minúsculas entidades insulares, al lado de Guinea Holandesa, otro pequeño dominio continental: estas tierras y sus pobladores (a lo sumo cien mil en su totalidad), tienen conciencia lingüística a partir de su idioma materno, el neerlandés, pero además poseen gran flexibilidad y preparación para la adquisición de otros idiomas: eso cuenta más que los números absolutos.

Pese al triunfalismo y a una innegable presión demográfica que hace avanzar más el spanglish que el español en Estados Unidos, éste no está por destronar el inglés como lengua oficial; tampoco ocurrirá con el impacto del inglés en el neerlandés, allá, con la ventaja de que éste, justamente por ser minoritario en el plano mundial, genera más conciencia linguiística en sus hablantes. En definitiva, frente a la cercanía aplastante del Tío Sam en todas las dimensiones, desde lo económico hasta lo ideológico, no basta un vago e idílico sentimiento colectivo de latinidad a la defensiva, basada ésta principalmente en adoración fetichista, pero superficial del español. Falta un manejo activo, contrastivo de otro idioma, de la denominación que sea. En América Latina existe solo una aparente contradicción entre, por un lado, una mundialización que se impone a pasos agigantados en todo tipo de estamentos y, por otro lado, una recomendable diversidad que florece por el rico sustrato étnico, con su variable de lo lingüístico. Si se comparan las mentes de habla neerlandesa y las hispanohablantes, ¿quiénes están más preparados? He allí la cuestión.

198 


\subsection{Ejemplos sorprendentes de efecto «global» del neerlandés}

Varios casos ya evocados subrayan mi postulado de que el siglo XVI, con el descubrimiento del otro mundo bajo égida española, significó para la mentalidad occidental una especie de primera globalización. En tres olas, quiero evocar ahora el caso similar de vocablos, generalmente reflejos de épocas más tardías, que igual prueban esa señalada mundialización léxica a la que contribuyó el neerlandés, pero no necesariamente a través del español.

Del siglo XVII, y como quien dice pensando especialmente en las poblaciones circumcaribeñas, allí está el vocablofilibustero. Proviene del neerlandés vrijbuiter, compuesto de vrij (libre) y buit/er (botín, el que lo hace), refiriéndose entonces a piratas de mar, sobre todo por las Antillas y principalmente en los siglos XVII y XVIII. Consumada la separación de los Países Bajos, es lógico pensar especialmente en el impacto holandés en el asunto, lo que nos recuerda la misma toponimia, al corroborar que Bluefields, en el Atlántico nicaragüense, proviene de Blauwveld, uno de los jefes de esos corsarios; los flamencos (es decir: los Países Bajos del Sur estaban «protegidos» por el Gobernador Farnese (el sucesor del temible Duque de Alba, hacia 1595), quien ya entonces tuvo que luchar contra «las cotidianas incursiones de los vrijbuiters holandeses, que operaban desde Ostende, Hulst y Breda» ${ }^{23}$. Las dos últimas ciudades formaban parte de los Países Bajos del norte y la primera, actualmente en Bélgica, pertenecía a Francia y tuvo históricamente mucho que ver con el filibusterismo; de hecho, todo flamenco, en el mismo idioma que el holandés, contará las glorias antiespañolas de otro legendario jefe filibustero: Piet Hein; hasta en el siglo xx, cantar esas hazañas era parte del folclor local.

En el presente contexto vale también evocar un siniestro Meneer («Señor», aquí con toda la carga sarcástica), que contribuyó a la página más negra del historial de relaciones diplomáticas entre Holanda y Costa Rica. Se trata del individuo con el muy neerlandés nombre de

$\overline{23} \quad$ En José Javier Ruiz Ibánez, «Monarquía, Guerra e individuo en la década de 1590: el socorro de Lier», Hispania. LvII, n 195 (1997), pp. 37-62. 
Eduard Mansvelt ${ }^{24}$, filibustero de allá, particularmente activo en la zona circumcaribe. Fue comisionado para atacar Curazao y entre 1665 y 1666 se dedicó a su «real oficio» por las costas de Cuba y el Reino de Guatemala. En 1665, su «colega» holandés Jan David, ya había saqueado Granada, en Nicaragua. Cuando visitó Costa Rica y Panamá tenía como lugarteniente al después más conocido Henry Morgan. Era una empresa verdaderamente multinacional compuesta entre otros también por flamencos ${ }^{25}$. Otra curiosidad histórica: desde Cartago lo enfrentó Juan López de la Flor y Reinoso, uno de los varios ${ }^{26}$ gobernadores, veteranos de las guerras de Flandes, entonces parte de los históricos Países Bajos.

Registro dos palabras provenientes del neerlandés, ahora con resonancia universal o por lo menos occidental, a partir de su inserción en el francés del siglo xviII. Por un lado tenemos «maniquí» que a pesar de diversas variantes no cuesta relacionar con un origen común: es el manneke, diminutivo de man, hombre, en el sentido genérico. Como en cualquier parte, también en Bélgica ha prevalecido una cierta deformación nacionalista de la historia, por lo cual, por influencia de los sectores largamente dominantes de habla francesa, por un lado se ha ignorado el común acerbo del «holandés» y del «flamenco» (con columna vertebral en común: el neerlandés) y por otro, se ha fabricado una artificial «unidad belga» ${ }^{27}$. Se exalta por ejemplo en uno de los símbolos nacionales por excelencia: el Manneken-Pis ${ }^{28}$ a un costado

$24 \quad$ Sobre ese tenebroso personaje, ver «El siniestro Meneer Mansvelt», evocado con fina ironía por Jorge Sáenz Carbonell en la columna histórica de la revista digital Tiquicia.com (con esa misma dirección), de la segunda quincena de diciembre del 2000; ver además el aporte del mismo autor en un libro por publicar, en el 2001, sobre las relaciones histórico-diplomáticas entre Costa Rica y los Países Bajos.

25 Ver «Los bucaneros retroceden», relato histórico de Ricardo Fernández Guardia, en Crónicas coloniales (San José: Editorial Costa Rica, 1967).

36 Siendo el más importante su predecesor, no inmediato, Gregorio de Sandoval, que llegó en 1636, después de servir al rey español largos años en Italia y Flandes.

27 Fue el gran valón y asesor del Rey Leopoldo II el que tuvo que recordarle al Rey de los Belgas: «Majestad. no existen los belgas, solo hay valones y flamencos» (los primeros, francófonos: los segundos de habla neerlandesa).

2* Se trata del «Hombrecito meando» que, según la «leyenda educativa» se puso a obrar (en todos los sentidos) en contra del invasor austriaco: recordar que los Países Ba jos meridionales pertenecieron al Imperio Austríaco en gran parte del siglo XVIII. 
de la Plaza Mayor en Bruselas. Lo cierto es que la moda francesa, promulgada como artesanía por la misma Encyclopédie, generaliza un instrumento de costura que ocupa un «hombre» (o mujer) artificial como modelo. Por otro lado, es también el mismo enciclopedismo francés (Voltaire) que generaliza el término «etiqueta» (en sentido diplomático de rango y respeto a normas formales establecidas), vocablo que remonta al neerlandés stikken, en el sentido de adherir (en inglés: stick), seguramente por algún tipo de distintivo que se pegaba en la ropa, visualizando una distinción..

Existe un tercer caso de «globalización verbal» originado en el siglo XVII, que vio su auge en el XIX, con la guerra de los boers y en el $\mathrm{xx}$, con un término tan connotado como apartheid. Esos vocablos se originaron en África del Sur, pero ahora son de uso casi universal. Provienen de situaciones muy peculiares que se desarrollaron allí. La primera palabra se refiere a un grupo beligerante, en lucha casi tipo guerrillero, contra el opresor inglés. Los que hemos sido boy-scout sabemos del caso por las evocaciones al respecto de Baden Powell. En todo el territorio del sur y del oeste africanos hay topónimos que siento propios, como Windhoek, Kaapstad (Ciudad del Cabo), Transvaal y Orange: son huellas de asentamientos holandeses, esencialmente campesinos, es decir, «boers « (boeren, en neerlandés más moderno). Se trata ahora de vocablos en afrikáans. Mi corrector electrónico se empeña en poner acento «extraño» a ese vocablo que considero «mío», por la simple razón de que el idioma en cuestión lo puedo leer y hablar con fluidez: es el neerlandés de esos campesinos; afrikaans le pondría yo, aunque ahora desde muchos puntos de vista puede considerarse una lengua independiente. Evolucionó a partir del neerlandés y recibió influencia del inglés, pero tampoco es tanto; lo mismo pasa con el francés de Canadá, pese a que este no se cataloga como un idioma aparte, sino una versión regional del francés. ¡Cuestión de interpretación! Lo cierto es que hasta en Centroamérica y las Antillas todo el mundo entiende cuando se evoca apartheid, porque corresponde a una mentalidad que dolorosamente no ha muerto. 


\subsection{El neerlandés en perspectiva europea, para el siglo $\mathrm{XXI}$}

Frente al relativo monolingüismo y cierta parálisis que prevalecen en América Latina en el contacto y el aprendizaje de otros idiomas, muy distinto es el panorama al otro lado del Atlántico. Veámoslo aquí en función del neerlandés. Allí históricamente han crecido las grandes lenguas occidentales. Por el eurocentrismo (que se puede lamentar, pero fue realidad desde la conquista hasta por lo menos la Segunda Guerra Mundial), esos vehículos comunicativos se volvieron universales. Cervantes, Dante y Shakespeare por su lengua y sus productos artísticos, cristalizan en sí toda una cultura. Respecto del francés y el alemán, como dirían los primeros «il n'y a que l'embarras du choix» (en la variedad está el gusto, diríamos en español), para indicar cantidad de escritores de primerísima fila, como exponentes de la categoría universal que ostenta su lengua. Del Mediterráneo hacia el norte, ninguna nación puede sentirse ajena a interferencia idiomática tanto dentro de sus fronteras, como por la influencia, aunque sea mediática, de varias lenguas. Especialmente en países de dimensiones geográficas reducidas, como Bélgica y Suiza, viven y conviven expresiones vernáculas muy diferentes.

El ciudadano europeo de habla neerlandesa está ante un gran reto. En primer lugar, ¿qué futuro le espera, en los próximos decenios a su lengua materna, teniendo en cuenta las enormes migraciones, no solo de mano de obra sino también de profesionales que la Europa sin fronteras internas, ni físicas ni monetarias ni de títulos, va a traer? En seguida, ¿qué va a pasar con la estructura demográfica de un continente no por nada llamado «viejo»? En tercer lugar, ¿cómo organizar a nivel «macro» europeo, la convivencia política, salvaguardando tanto la eficacia como la auténtica democracia, es decir el respeto precisamente a las minorías, incluidas las lingüísticas? Todas esas preguntas son de candente actualidad.

Respecto de lo primero, la zona de habla neerlandesa de Bélgica, lo mismo que los Países Bajos, tienen tanto extensos programas de incorporación del forastero, en el plano idiomático, como conciencia 
propia en consideración de la necesaria preparación frente a la interferencia de lenguas que se acelerará: aparte de que desde la primara se enseña otro idioma, en la secundaria se suele llevar un tercero, sin descuido de los anteriores y no es raro, en ambos países, que muchos programas universitarios, sobre todo a nivel de posgrado, impliquen como requisito el conocimiento de varias lenguas o que estos se den, de una vez, en inglés. Toda esta preparación activa se da no solo por medio del circuito formal educativo, sino además vía los medios de comunicación informales que literalmente forman un concierto polifónico.

Lo segundo constituye un temor no conf esado de todo europeo, en general, frente a índices que se presentan fuera de ese ámbito. Aplicando lo anterior al caso que nos ocupa, la pirámide demográfica tampoco favorece, comparativamente hablando, la cantidad de habitantes de habla neerlandesa. La zona de habla neerlandesa de Bélgica apenas si logra evitar el drama (psicológico y para las pensiones): caer en cifras de crecimiento negativo. Pese a una lamentable xenofobia, los inmigrantes mismos, entre otros, alivian el problema a corto y mediano plazo; pero su vecino al norte, felizmente lleva a cabo una política mucho más activa en este sentido, siendo el país europeo que más aumenta el índice de población, estimulando su propio crecimiento y acogiendo de manera inteligente a grupos externos.

Lo más complejo es el tercer punto: la operatividad política europea, teniendo en cuenta su propia expansión, salvaguardando el mosaico interno: una dificultad histórica, al mismo tiempo que una riqueza para el futuro. En lo interno, la misma zona de habla neerlandesa no corresponde con la extensión, acumulada, de los Países Bajos y Bélgica. Este país topa con la compleja situación del bilingüismo, con el francés oficial del sur, pero también están el caso complicado del alemán, la lengua constitucional de más de cien mil belgas en el este, y el peliagudo estatuto de Bruselas, capital europea; en los Países Bajos está la realidad del frisón en el norte. El gran debate europeo viene provocado por la ampliación de 15 a 27 Estados al menos, emparejada con urgentes «cambios de arquitectura» 
que se imponen. La Unión Europea corre el riesgo de ser un laberinto, una nueva Babel, donde cada comunicación no solo se vuelve incomprensible, sino que todo y más de lo que se ahorra con la moneda única se pierde en intérpretes, traducciones y papeles. Respecto del neerlandés, constituye uno de los once idiomas oficiales, pero no es una de las lenguas de trabajo. Es la sexta lengua en importancia en la UE, después del inglés, el alemán, el francés, el español y el italiano, en ese orden, antes de las lenguas escandinavas, por ejemplo. Técnicamente no es una lengua minoritaria pero tampoco forma parte del paquete de las grandes.

Resulta fácil, desde fuera, diagnosticar o proponer que todo podría resolverse con el inglés, lengua de por sí, se piensa, de carácter universal. La solución evidente sería hacer que el idioma de Shakespeare, hablado en este momento por casi el $55 \%$ de los ciudadanos de la UE, fuera el de trabajo, como el latín en la Europa medieval. Hay mucho más bilingüismo y mucho más capacidad políglota en Europa que en el área de Centroamérica y el Caribe, pero tampoco conviene ilusionarse demasiado, sobre todo en cuanto a niveles de conocimiento en capas poblacionales de escasa escolaridad. Respecto del paralelo con el latín, este idioma no lo hablaba nadie, como lengua matema; en cambio los ingleses, menos europeístas que otros, justamente saldrían premiados, aparte de que no contaría con la aprobación de las «grandes» lenguas y sus representantes, como el alemán (poderosa, ahora con un país reunificado), el francés y el español. Todo eso está en discusión para los políticos de alto nivel, pero ¿qué pasará con el ciudadano común? Una cosa es la lengua para los negocios o la diplomacia y otra, que la gente se sienta a gusto. La expresión idiomática de veintiún millones de ciudadanos de Flandes y de los Países Bajos tiene su peso, desde luego, pero representa el 20\% de los casi cuatrocientos millones de europeos que se preparan para vivir y crear juntos el siglo xxI. Europa tiene ante sí un reto enorme, entre el dinamismo y el salvaguardar de su riqueza expresiva. 


\section{Conclusión general}

El caso del neerlandés no es como el del español y no es una lengua más difícil u oscura que éste; cada lengua of rece su riqueza interna, como vehículo de comunicación y de creación artística. Este artículo ha resaltado lo bueno de la diversidad, lo rico de la polifonía y que «todos los seres humanos seremos hermanos» como cantó Schiller y ahora, al unísono, en coro polifónico, toda la Unión Europea. Con su brazo tecnológico, la globalización ha supuesto nuevos retos y nuevas posibilidades, también en lo idiomático. Se vuelve el interés por lo local, regional, sostenido por la lengua, la etnia. Partiendo de una rica herencia, hoy el pueblo y la cultura de habla neerlandesa revindican además una especificidad y una identidad en el concierto regional y mundial. 